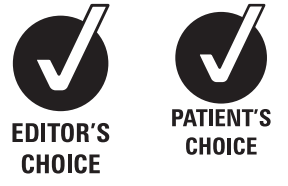

See Editorial commentary, p 868 and p 869

${ }^{1}$ Department Clinical Neurosciences, University of Edinburgh, Edinburgh, UK ${ }^{2}$ Newcastle University School of Medicine, Newcastle Upon Tyne, UK

${ }^{3}$ Department of Psychiatry, University of Edinburgh, Edinburgh, UK

${ }^{4}$ Neurorehabilitation, Astley Ainslie Hospital, Edinburgh, UK

Correspondence to Dr Jon Stone, Department Clinical Neurosciences, Western General Hospital, Edinburgh EH4 2XU, UK; jon.stone@ed.ac.uk

Received 19 March 2012 Revised 20 April 2012 Accepted 24 April 2012

\title{
'A Leg to Stand On' by Oliver Sacks: a unique autobiographical account of functional paralysis
}

\author{
Jon Stone, ${ }^{1}$ Jo Perthen, ${ }^{2}$ Alan J Carson ${ }^{3,4}$
}

\section{ABSTRACT}

Oliver Sacks, the well known neurologist and writer, published his fourth book, 'A Leg to Stand On', in 1984 following an earlier essay 'The Leg' in 1982. The book described his recovery after a fall in a remote region of Norway in which he injured his leg. Following surgery to reattach his quadriceps muscle, he experienced an emotional period in which his leg no longer felt a part of his body, and he struggled to regain his ability to walk. Sacks attributed the experience to a neurologically determined disorder of body-image and bodyego induced by peripheral injury. In the first edition of his book Sacks explicitly rejected the diagnosis of 'hysterical paralysis' as it was then understood, although he approached this diagnosis more closely in subsequent revisions. In this article we propose that, in the light of better understanding of functional neurological symptoms, Sacks' experiences deserve to be reappraised as a unique insight in to a genuinely experienced functional/ psychogenic leg paralysis following injury.

\section{A TRAUMATIC INJURY}

Ten years before he wrote his book, A Leg to Stand $\mathrm{On}^{1}{ }^{1} 2$ Sacks was hiking in Norway when he sustained a severe leg injury. On an isolated mountain path he stumbled upon a bull and as he fled from the animal he fell and found himself "lying at the bottom of a short sharp cliff of rock, with my left leg twisted grotesquely beneath me, and my knee in such pain as I had never, ever known." Finding himself "terrifyingly and seriously alone", he formed a makeshift splint for his "utterly useless" injured leg from his umbrella and anorak and partially descended down the mountain. Sacks described a sense of being near to death and talks about the leg as an object which was "stupid, senseless... out of control"

He was eventually rescued by reindeer hunters, put in a temporary cast and reached a hospital in London, where his leg was successfully operated on to repair an avulsed quadriceps tendon. Postoperatively he spent two days "feverish, shocked and toxic, and there was intense pain in my knee...I had periods of delirium...I felt horribly sick." He described "the systematic depersonalization which goes with becoming a patient." It was clearly a painful, fearful and distressing experience.

\section{A "CYLINDER OF CHALK"}

During his first session with the physiotherapist, he found himself unable to tense his left quadriceps muscle. He hints at a central problem: "I couldn't think how to contract the quadriceps any more. I couldn't 'think' how to pull the patella, and I couldn't 'think' how to flex the hip. I had the feeling that something had happened, therefore, to my power of 'thinking' although only in regard to this one single muscle. Feeling that I had 'forgotten' something-something quite obvious, absurdly obvious, only it had somehow slipped my mind."

Sacks recognised immediately that his condition was not simply a physical injury confined to his leg: "What was now becoming frightfully, even luridly, clear was that whatever had happened was not just local, peripheral, superficial-the terrible silence, the forgetting, the inability to call or recall-this was radical, central, fundamental. What seemed, at first, to be no more than a local, peripheral breakage and breakdown now showed itself in a different, and quite terrible, light - as a breakdown of memory, of thinking, of will-not just a lesion in my muscle, but a lesion in me."

He describes in detail an intense feeling of disconnection from his injured leg. He was particularly alarmed by an incident where his leg was found hanging off the side of the bed when he thought it was straight in front of him. He asked the nurse to test his leg proprioception and discovered it was entirely absent in the left leg, apparently as far as the hip: "I knew not $\boldsymbol{m y} \mathbf{l e g}$. It was utterly strange, not-mine, unfamiliar. I gazed upon it with absolute non-recognition....The more I gazed at that cylinder of chalk, the more alien and incomprehensible it appeared to me. I could no longer feel it was 'mine', as part of me. It seemed to bear no relation whatever to me. It was absolutely not-me-and yet, impossibly, it was attached to me-and even more impossibly, 'continuous' with me." Sensory loss was to all modalities in the whole leg; "There was absolutely no sensation whatever...it looked and felt uncannily alien-a lifeless replica attached to my body." Later, when he had his stitches taken out he felt nothing stating, "I could have stuck a knife in to it for all the feeling it had."

Sacks' depersonalisation from his leg extended to his procedural memory; "I could no longer remember having a leg. I could no longer remember how I had ever walked and climbed." With hindsight he described his state at that time as "stewing in confinement, passivity, immobility."

\section{WALKING - AN AUTOMATIC PROCESS}

Sacks' first attempt to walk, 18 days after the accident, was a bewildering and bizarre experience. He found that he was only able to contract his quadriceps when he was not consciously attending to it. Contraction only occurred when "there was no 
cogitation, no preparation, no deliberation, whatever; there was no 'trying'...But when I tried...nothing happened at all."

Further, he was hampered by depersonalisation symptoms; "The unreality was still extreme. It wasn't 'my' leg I was walking with, but a huge, clumsy prosthesis (or hypothesis), a bizarre appendage, a leg-shaped cylinder of chalk .... as if I was operating a peculiarly clumsy, and unstable, robotic contraption, an absolutely ludicrous artificial leg." Walking had become a highly voluntary effort; "a matter of the most elaborate and exhausting and tedious computation" rather than the automatic, fluid movement it should be.

His interactions with his physiotherapist provided further useful insights; "I know how much you're trying", (the physiotherapist) said. 'And yet, it's like you're not trying at all. You put out all this effort-but somehow the effort isn't managing to do things...This was very much what I felt myself. I felt the effort diffuse uselessly, unfocussed as it were. I felt that it had no proper point of application or reference. I felt that it wasn't really 'trying', wasn't really 'willing'-because all willing is willing 'something' and it was precisely that 'something' which was missing..."

A significant breakthrough came when he began to hear Mendelssohn's violin concerto in his head; "And, as suddenly, without thinking, without intending whatever, I found myself walking, easily-joyfully, with the music...In this self-same moment the leg came back." The music appears to have distracted him from the act of walking, so that he could walk "without any conscious thought or calculation." However, the improvements were initially temporary with relapses, "as suddenly as if the needle had been lifted from a record...my walking stopped too."

\section{DIAGNOSTIC LIMBO}

Sacks, bewildered by these experiences, sought answers from his doctors. "Desperately now, I wanted communication, and reassurance,...I myself needed to communicate above all to my physician and surgeon: I needed to tell him what had happened to me, so that he could say, 'Yes, of course, I understand.'" But when he tried to talk to his surgeon, his concerns were dismissed "[there is] nothing wrong [with his leg]."

He met other patients who had had similar bodily experiences, and found that none had been able to discuss it with their surgeon. "Some had been terrified, others mildly scared; a few, stolid or stoic, seemed indifferent...If, indeed, I was 'unique', it was not in regard to the experience or its character, but only in the reflection, the ceaseless thought, I brought to it." By way of contrast he also met a patient with a phantom limb who told him "Doc here's got a leg, but no feeling in the leg-and I've got the feeling but no leg to go with it!"

\section{A DIAGNOSIS?}

Sacks considered a number of possible diagnoses for this problem. His initial thought was that he had experienced a disturbance of body image in the brain, losing the leg as an 'internal object'. He wondered briefly if this might be a form of cortical neglect caused by a postoperative right parietal stroke, but quickly discounted this when he remembered he could still move his toes. "My brain was alright...I didn't know what I did have, but I didn't have a stroke."

In any case, Sacks' unawareness of his leg was strikingly different to that of neglect. The core feature of neglect is lack of awareness or attention directed to the problem. By contrast, he was excessively aware, and excessively attending to it. A nocturnal hemianopic migrainous aura arising out of a horri- fying dream led him to compare his migrainous visual scotoma to his leg symptoms; "I have a scotoma for the leg! What I am experiencing with half my visual field is essentially similar to what I am experiencing with my leg. I have lost the 'field' for my leg precisely as I have lost part of my visual field."

Sacks discovered that his experiences were not unique, and subsequently met hundreds of patients with similar experiences; "it became clear that my own experiences had been typical, exemplary. Like myself, every such patient went through a profound ontological experience-dissolutions or de-realizations of being in the affected areas, associated with an elemental anxiety and horror; followed (if they were fortunate enough to recover) by an elemental sense of 'rerealization' and joy." He described plans to write up this case series but, as so many of us have experienced, this seems to be one project that didn't make it out of the drawer.

Although the alienation had gone within 4 weeks of his injury, his walking still had not returned to 'normal'. Sacks records the opinion of a Harley Street surgeon. "the alienation-it is a common phenomenon I often see it in my patients and I warn them beforehand." The surgeon dispatched him in a taxi to a swimming pool with instantaneous results. On reviewing Sacks the next day much recovered, the surgeon comments "What one needs is spontaneity, to be tricked in to action."

However, despite many such allusions to a central mechanism and a disturbance of body image Sacks did not initially reach a firm conclusion about his own diagnosis. In a footnote half way through the first edition Sacks attributes the problem in part to a peripheral lesion after all. He describes how a neurophysiology 4 years after the injury showed "quite severe denervation of the quadriceps and marked impairment of conduction in the femoral nerve which supplies it. At the time of my 'alienation', my scotoma, these impairments must have been profound or absolute."

On the possibility of hysteria, he was anxious that his friend AR Luria would not think he was 'hysterical, mad' and relieved when instead he wrote that 'he believed $m e$ ' and was 'discovering a new field'. Here the use of hysterical may have been more vernacular than medical but the passage emphasises a common concern among patients with symptoms that are hard to explain.

In a footnote in a subsequent edition Sacks provided the following rationale for why his symptoms were not "hysterical."

"Neuropsychological syndromes are 'bottom-up' disorders, in which a lower-level neurological disorder causes a higher-level psychological one. Hysteria, by contrast, is a 'top-down' disorder, where the primary disturbance occurs at the highest level-in higher-order consciousness, which is symbolic and linguistic-any disturbance at lower levels being secondary to this. There is a primary disturbance of local mapping and primary consciousness in 'alienation', but no primary disturbance of these in hysteria. (There could, of course, be some secondary disturbance.) Higher-order consciousness (which includes the psychoanalytic 'unconsciousness') is charged with specific, intense affects in hysteria-whereas it is merely bewildered in alienation."

He did however write how his own post-traumatic paralysis was similar to that described by Weir Mitchell as a 'negative phantom', by Babinski as the 'syndrome physiopathique'3 and by Leont'ev and Zaporozhets as an 'internal amputation'. ${ }^{4} \mathrm{He}$ expresses his exasperation at the tendency of 'classical neurology' to ignore the unusual experiences (eg, feelings of alienation) of their patients, instead being "strictly confined to observing gross structure and function." In concluding the book, Sacks attacks the mind/body dualistic thinking that still pervades neurological thought. He writes that "clinical and personal experience - an experience such as I relate in this book-is 
totally incompatible with (duality); it shows the bankruptcy of the classical model."

\section{THE DIAGNOSIS REAPPRAISED-FUNCTIONAL PARALYSIS?}

Sacks' description has numerous features in keeping with a diagnosis of functional paralysis, ${ }^{5}$ also called psychogenic paralysis, conversion disorder (DSM, Fourth Edition), dissociative motor disorder (ICD-10) and (at the time he had his injury) hysterical paralysis. Sacks' symptoms are clearly genuine and we share his exasperation with the dualism, that is, inherent in so many of the diagnostic labels just listed. Nonetheless, he only discusses his symptoms in the context of other patients who experienced their paralysis after injury. Our reappraisal of his diagnosis as functional paralysis is not an attempt to 'downgrade' his experience but to 'upgrade' the experience of the large number of people who develop functional paralysis in situations other than after physical injury.

Although he had clearly injured his quadriceps tendon, his postoperative inability to move his leg could not be explained on the basis of his orthopaedic injury or any structural neurological lesion. Although the first edition places weight on a femoral nerve injury as an explanation, in a later edition of the book Sacks reflects that the denervation of the quadriceps could not explain the global motor and sensory deficit of his original symptoms or the highly variable nature of movement during his recovery. There was a clear description of sensory loss to all modalities of the whole leg, including dramatic proprioceptive loss as high as the hip, which cannot be explained by anything other than a functional disorder. Later he is described as having lost hip flexion. Most impressive are his detailed and varied descriptions of depersonalisation and loss of ability to control left leg. His inability to 'will' the leg in to action is mirrored in the often quoted 1873 phrase from Paget ${ }^{6}$ who described the problem in hysterical paralysis as:

"She says, as all such patients do, 'I cannot'; it looks like 'I will not'; but it is 'I cannot will'"

Very typically for a patient with functional paralysis, he found that the more he concentrated on moving an affected limb, the harder it was to move. Distraction and rhythmic techniques, such as those provided by music, are sometimes effective tools to enable movement (indeed this is the basis of Hoover's sign and the tremor entrainment test ${ }^{7}$ ) or improve gait. His gradual and relapsing recovery is also typical.

The onset of Sacks' symptoms coincides with factors that have been associated with functional paralysis, an 'organic' injury (in this case causing leg weakness) a physical injury, pain, fear and a general anaesthetic. ${ }^{8}$ In a systematic review of 869 patients with functional motor symptoms, in 133 studies we found that $37 \%$ were reported in association with a physical injury, usually described without comment. ${ }^{9}$ In another study of 107 patients, recently published in the Journal of Neurology, Neurosurgery and Psychiatry, we found many of the factors experienced by Sacks to be present at onset of symptoms. ${ }^{8}$ The complex relationship between pain, injury and functional symptoms has been an ongoing controversy for over 150 years involving railway spine, 'traumatic hysteria' of the late 19th century, shell shock, reflex sympathetic dystrophy/complex regional pain syndrome and whiplash and does not need repeating here. ${ }^{10}$

Sacks' frustration in finding a health professional to understand his frightening symptoms is common, as too is his rejec- tion of the possibility of a psychological component to the problem. ${ }^{5}$

Hysteria as understood, medically, in the 1970s and even early 1980s was not the same as functional/psychogenic paralysis is understood now. ${ }^{11}$ At that time psychodynamic theories held sway and, as Sacks describes, the conception of a hysterical symptom was a symbolic event induced by intrapsychic conflict related to a psychological trauma. The kinds of events typically sought by a psychiatrist would be a recent interpersonal or childhood stressor and not the pain and depersonalising experience of a torn quadriceps. The diagnosis of hysteria was avoided by neurologists, partly for fear of misdiagnosis but mostly through lack of interest or contempt for the problem. ${ }^{11}$ It is hardly surprising that Sacks did not consider this a good fit for his symptoms. There is a strong argument that he was right to reject the diagnosis of 'hysteria', as it was described at that time, even if the evidence for a 'non-organic' problem was overwhelming. In recent years a broader biopsychosocial view of functional paralysis has emerged as a disturbance in body image, in many ways complementary to phantom limb syndrome, as Sacks' fellow patient at the time suggested. Functional brain imaging, although in its infancy in relation to this symptom, is helping to harmonise neurological and psychological aspects of this symptom and is working towards differentiating the problem from deliberate simulation, ${ }^{12}{ }^{13}$ although this still lingers as a concern among many neurologists. ${ }^{14} 15$ Simultaneously there are efforts to destigmatise and provide support for patients with these symptoms such as the website http://www. neurosymptoms.org edited by one of the authors. We emphasise that our reappraisal of Sacks' problem is not intended to challenge the reality of his symptoms. Neither are we suggesting that there was some hidden psychological stressor that Sacks has forgotten. On the contrary, his vivid description, like our many patients, provides clear evidence of their genuine nature and how commonly they are triggered by painful physical injury alone.

But can doctors, who in all specialities routinely see patients with functional symptoms, really get functional symptoms themselves? Aren't they 'vaccinated' against it somehow by knowing about it? Apparently not. The authors of this article have managed several doctors as patients with dramatic functional neurological symptoms including quadriplegia imitating Guillain-Barré syndrome. In a recent survey of UK neurologists, seven $(2 \%)$ said they had experienced a conversion symptom themselves prior to entering medicine. ${ }^{15}$

Sacks' detailed description of functional paralysis in 'A Leg to Stand On' is unique and invaluable for patients and doctors alike. Patients we have recommended the book to have found it helpful to see their own unusual depersonalisation symptoms described so skilfully, and also that recovery is possible with the right approach.

Contributors JS conceived the article, all authors contributed to writing

Competing interests None.

Provenance and peer review Not commissioned; externally peer reviewed.

\section{REFERENCES}

1. Sacks OW. A Leg to Stand on. New York: Harper \& Row, 1984

2. Sacks OW. The Leg. Vol. 4. London Review of Books, 1982:3-5

3. Babinski J, Froment J. Hysteria or Pithiatism. (Trans. by JD Rolleston). London: Univ of London Press, 1918.

4. Leont'ev AN, Zaporozhets AV. Rehabilitation of Hand Function. (Transl. Basil Haigh). New York: Pergamon Press, 1960.

5. Stone J, Warlow C, Sharpe M. The symptom of functional weakness: a controlled study of 107 patients. Brain 2010;133:1537-51. 
6. Paget J. Nervous mimicry. In: Paget S, ed. Selected Essays and Addresses by Sir James Paget. London and New York: Longmans, Green and Co, 1873.

7. Stone J. The bare essentials: functional symptoms in neurology. Pract Neurol 2009:9:179-89.

8. Stone J, Warlow C, Sharpe M. Functional weakness: clues to mechanism from the nature of onset. J Neurol Neurosurg Psychiatry 2012;83:67-9.

9. Stone J, Carson A, Aditya $\mathrm{H}$, et al. The role of physical injury in motor and sensory conversion symptoms: a systematic and narrative review. J Psychosom Res 2009:66:383-90.

10. Trimble MR. Post-Traumatic Neurosis: from Railway Spine to the Whiplash. Chichester: John Wiley \& Sons, 1981
11. Stone J, Hewett $R$, Carson A et al. The 'disappearance' of hysteria: historical mystery or illusion? J R Soc Med 2008;101:12-18.

12. Voon V, Gallea C, Hattori N, et al. The involuntary nature of conversion disorder. Neurology 2010;74:223-8

13. Cojan Y, Waber L, Carruzzo A, et al. Motor inhibition in hysterical conversion paralysis. Neuroimage 2009;47:1026-37.

14. Kanaan R, Armstrong D, Barnes P, et al. In the psychiatrist's chair: how neurologists understand conversion disorder. Brain 2009;132:2889-96

15. Kanaan RA, Armstrong D, Wessely SC. Neurologists' understanding and management of conversion disorder. J Neurol Neurosurg Psychiatry 2011;82:961-6.

\section{DIFFERENTIAL DIAGNOSIS}

\section{Trustworthy guidance on your iPhone}
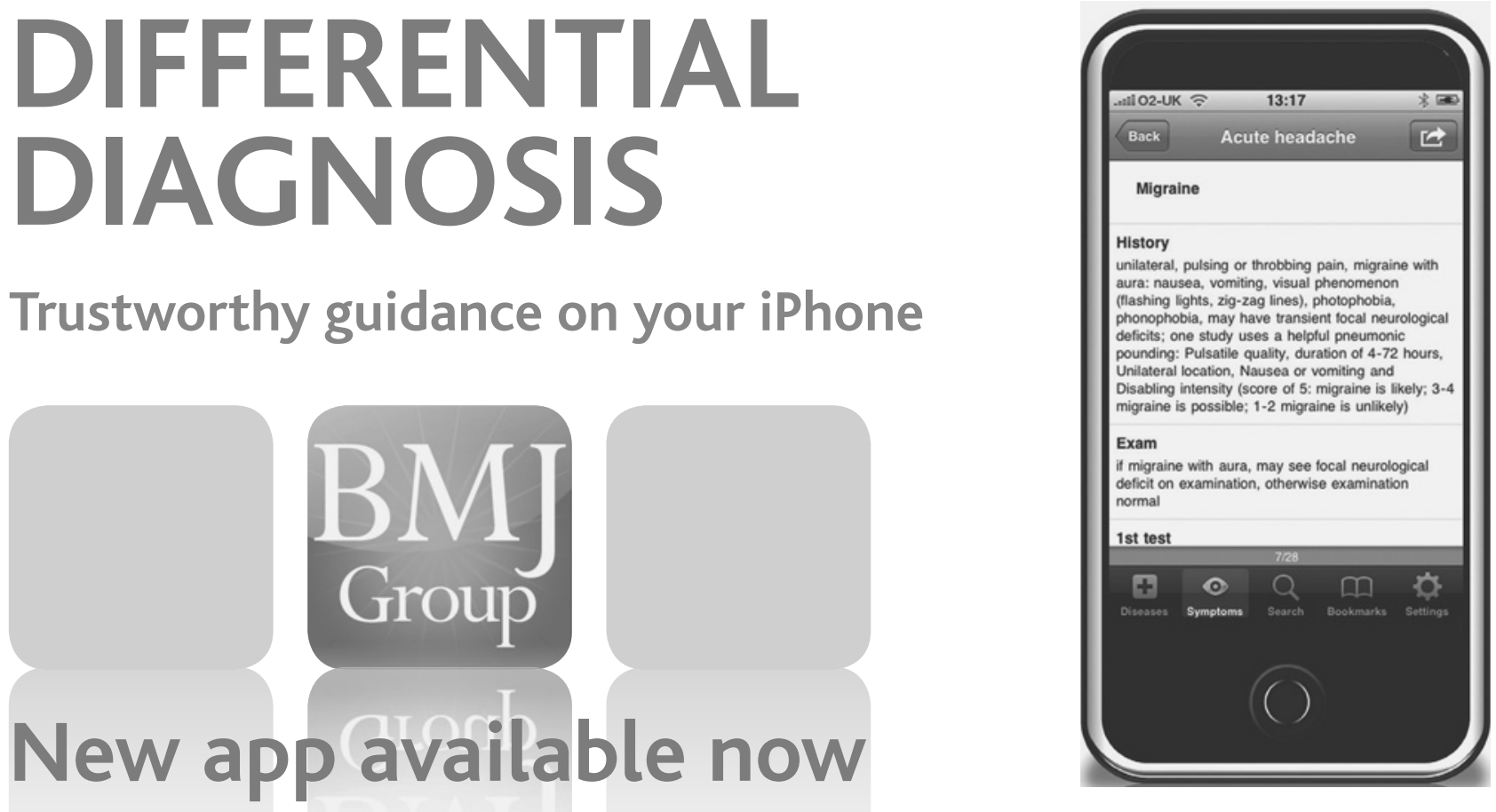

Find out more at bestpractice.bmj.com/differentials 